\title{
Syringopleural Shunt Insertion Using a Minimally Invasive Approach: Technical Note, Case Series, and Review of the Literature
}

\author{
Kaiyun Yang ${ }^{1}$, Yosef Ellenbogen ${ }^{1}$, Chirayu Bhatt ${ }^{2}$, Majid Aljoghaiman ${ }^{1,3}$, Nirmeen Zagzoog ${ }^{1}$, Kesava Reddy $^{1}$ \\ ${ }^{1}$ Division of Neurosurgery; Department of Surgery, McMaster University, Hamilton, Ontario, Canada \\ ${ }^{2}$ University of Ottawa; Faculty of Medicine, Ottawa, Ontario, Canada \\ ${ }^{3}$ Division of Neurosurgery; Department of Surgery, King Faisal University, Saudi Arabia
}

Received: March 2, 2021

Revised: April 27, 2021

Accepted: May 16, 2021

Corresponding Author: Majid Aljoghaiman, MBBS

Division of Neurosurgery,

Department of Surgery, McMaster

University, 1280 Main St W,

Hamilton, ON L8S 4L8, Canada

Tel: +1-437-989-6477

Fax: +1-905-521-9992

E-mail:majid.aljoghaiman@

medportal.ca

Presentations: This study was presented in abstract form at the 53rd Canadian Neurological Sciences Federation 24-27 June 2018, Halifax, NS, Canada.

\begin{abstract}
Objective: Syringomyelia is a rare neurosurgical condition that could benefit from insertion of a syringopleural shunt in selected symptomatic cases. Treatment of syringomyelia through minimally invasive intervention is an attractive alternative to open approach. The objective of this report is to demonstrate the technical aspect, assess the feasibility, outcomes, and complications of syringopleural shunt insertion through minimally invasive surgical (MIS) approach.

Methods: Single-center retrospective chart review was done on patients with syringomyelia who underwent insertion of syringopleural shunts using the Metrx Quadrant ${ }^{\mathrm{TM}}$ retractor system from January 1, 2008 to April 1, 2020. A technical report of the steps of the surgical intervention is also described.

Results: Ten procedures were performed on 9 patients with a mean follow-up of 7.2 years. The etiologies of syringomyelia included post-traumatic, Chiari malformation, idiopathic, and diastematomyelia. All patients underwent correction of underlying etiologies prior to insertion of syringopleural shunts. Six patients (67\%) had sustained neurological improvement, and 3 (33\%) had halted progression of myelopathy. One patient was admitted for urgent removal of newly inserted syringopleural shunt due to immediate postoperative neurological decline and subsequently returned to their neurological baseline. The remaining eight patients were discharged on the same day of surgery.

Conclusion: Minimally invasive techniques have not been widely utilized in the treatment of syringomyelia. Our case series presents a novel, minimally invasive technique for the insertion of a syringopleural shunt, with reduced hospital stay and durable outcomes. Further, our series demonstrates that this technique is feasible and safe in appropriately selected patients.
\end{abstract}

Key Words: Syringomyelia, Ventriculo-peritoneal shunt, Minimally invasive surgery

\section{INTRODUCTION}

Syringomyelia is a condition characterized by the presence of an abnormal fluid-filled cavity (syrinx) within the spinal cord. It affects mainly children and young adults with prevalence estimated at be 8.4 to 90 per 100,000 [1-4]. Syringomyelia can

Copyright (C) 2021 Korean Minimally Invasive Spine Surgery Society

This is an Open Access article distributed under the terms of the Creative Commons Attribution Non-Commercial License (http://creativecommons.org/licenses/by-nc/4.0/) which permits unrestricted non-commercial use, distribution, and reproduction in any medium, provided the original work is properly cited. 
be found at any anatomical locations from the high cervical spinal cord to the conus medullaris. Etiologies include Chiari malformation, trauma, neoplasm, and arachnoiditis; however, in several cases, it is idiopathic [5].

The natural progression of syringomyelia is slow in the majority of cases and about $50 \%$ of patients show no progression over 10 years in some series, therefore, it is frequently conservatively managed, particularly in asymptomatic patients $[6,7]$. Surgical treatment is warranted in patients presenting with progressive myelopathy. Symptomatic patients typically present with segmental pain and dissociated sensory loss often in the well-described "cape" distribution, followed by progressive asymmetrical weakness [8]. Other signs and symptoms may include asymmetrical deep tendon reflexes, hyperhidrosis, autonomic dysreflexia, Horner's syndrome, dysphagia, central sleep dysfunction, and cardiorespiratory dysfunction [9].

Syringomyelia can be treated by correcting the underlying etiology or through direct drainage and shunting into the peritoneal, pleural, or subarachnoid spaces [9]. Syringoperitoneal shunts allow easy absorption of cerebrospinal fluid (CSF); however, they are technically more difficult to perform as they require the patient to be in the lateral decubitus position. On the other hand, syringopleural shunts are a good option when the patient's pulmonary reserve is adequate [10].

Traditional open approaches to shunting of syringomyelia require subperiosteal stripping of the paraspinal musculature, which is associated with postoperative pain, hospital admission, and slow mobilization, as well as increased difficulties with wound healing [11-13]. Thus, minimally invasive surgical (MIS) approaches to treating syringomyelia are attractive alternatives to open approaches. Several reports have described MIS technique for insertion of syringosubarachnoid shunts [1416], however reports on syringopleural shunts are scarce. Here, we report our experience for MIS insertion of syringopleural shunts, and discuss other reported experiences of MIS syringopleural shunting in literature [17,18].

\section{METHODS AND MATERIALS}

\section{Patient Selection}

We conducted a single-center retrospective chart review on patients with syringomyelia who were treated with a novel MIS approach for insertion of syringopleural shunts using the METRx Quadrant ${ }^{\mathrm{TM}}$ retractor system (Medtronic, Memphis, TN) from January 1, 2008 to April 1, 2020. All the operations were performed by the senior author after correction of under- lying etiologies. Patients' characteristics, baseline preoperative symptoms, neurological outcomes and follow up are reported.

\section{Ethics Approval}

Approval from the institutional research ethics board was obtained (IRB number 1506). Due to the retrospective nature of the study, formal consent was not required.

\section{Illustrative Case and Surgical Technique}

A 30-year-old man was referred to the neurosurgery service with a 3-month history of progressive numbness in the right side of his neck along with paresthesia in the right hand and burning sensations in the right arm. His past medical history was significant for an ASIA-A spinal cord injury following a motor vehicle accident 13 years prior at the level of T6, for which he had a thoracic decompression and instrumented fusion. Two years after the initial trauma, he had a syringo- subarachnoid shunt placed at the level of T10 for the treatment of symptomatic post-traumatic syringomyelia. When he presented with new, right arm sensory disturbances, the physical exam was significant for paraplegia, and right-sided sensory impairment to light touch which extended to the level of C3. MRI of the spine revealed the syrinx had enlarged compared to the previous images (Figure 1A, B).

Given the progressive neurological decline, the patient accepted to proceed with surgical intervention which involved the insertion of a syringopleural shunt at the level of T5, which was the point of the maximal diameter of the syrinx. During the procedure, lateral fluoroscopy was used to guide the placement of a Kirschner wire on the T5 lamina. A series of dilators were used with sequentially increasing size until a $22 \mathrm{~mm}$ dilator size was reached. This was followed by the placement of a $22 \mathrm{~mm}$ METRx Quadrant ${ }^{\mathrm{TM}}$ retractor (Medtronic). Under the microscope, we performed a hemilaminectomy to expose the dura (Figure 2A). We then performed a midline durotomy (Figure $2 \mathrm{~B})$, and subsequently a dorsolateral myelotomy where the syrinx came closest to the pial surface. The proximal end of a lumboperitoneal shunt tubing (Medtronic; barium impregnated) was inserted into the syrinx. The tubing was secured in place with the help of a double-ended 6-0 Prolene suture (Ethicon) through the dural edges (Figure 2C) using a Castroviejo needle holder and a knot pusher. With satisfactory position of the proximal catheter, the dura was closed in a water-tight fashion (Figure 2D). A tissue sealant (e.g., DuraSealTM) was used at this stage to reinforce the dural closure. The Quadrant ${ }^{\mathrm{TM}}$ retractor 

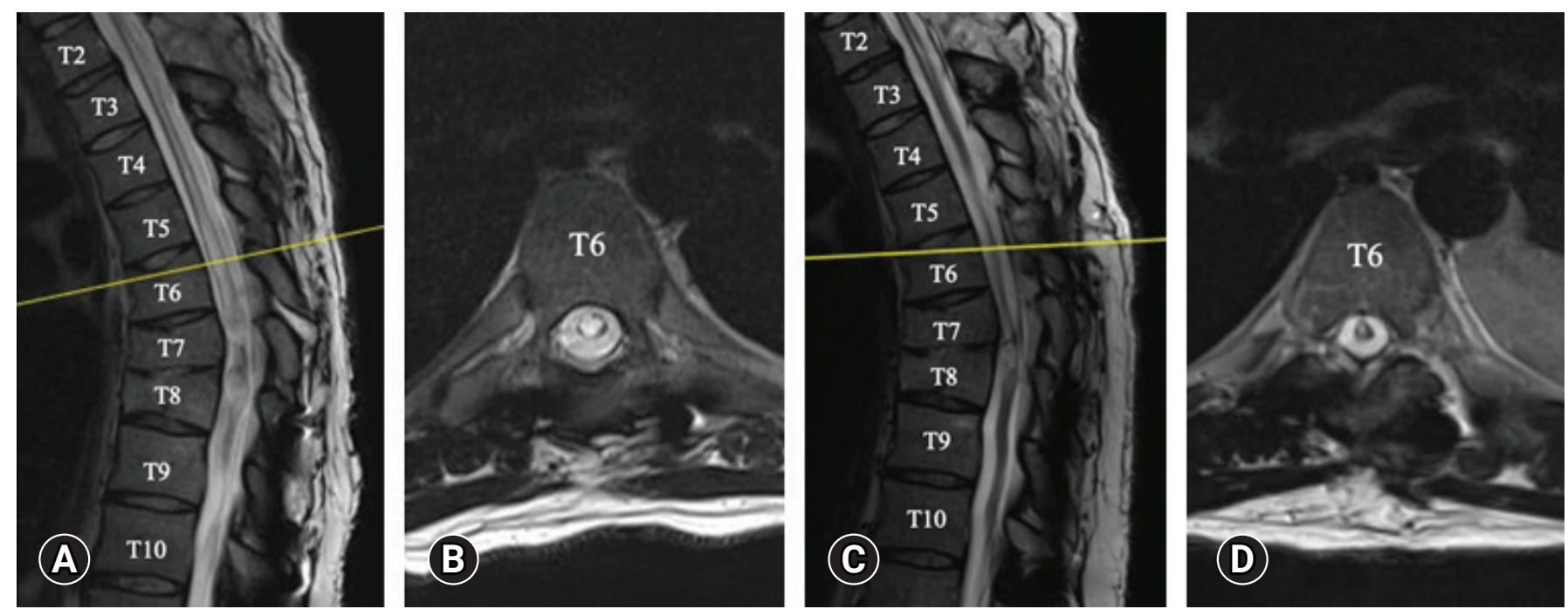

Figure 1. T2-weighted MRI of the spine. Pre-operative: $(A)$ sagittal and (B) axial images of the spine demonstrating the thoracic syrinx. Cross-section of T6 is shown to demonstrate the approximate area of maximal syrinx diameter. Six months post syringo-pleural shunt insertion: (C) sagittal and (D) axial images of the spine showing the syrinx has collapsed in comparison to the preoperative images.
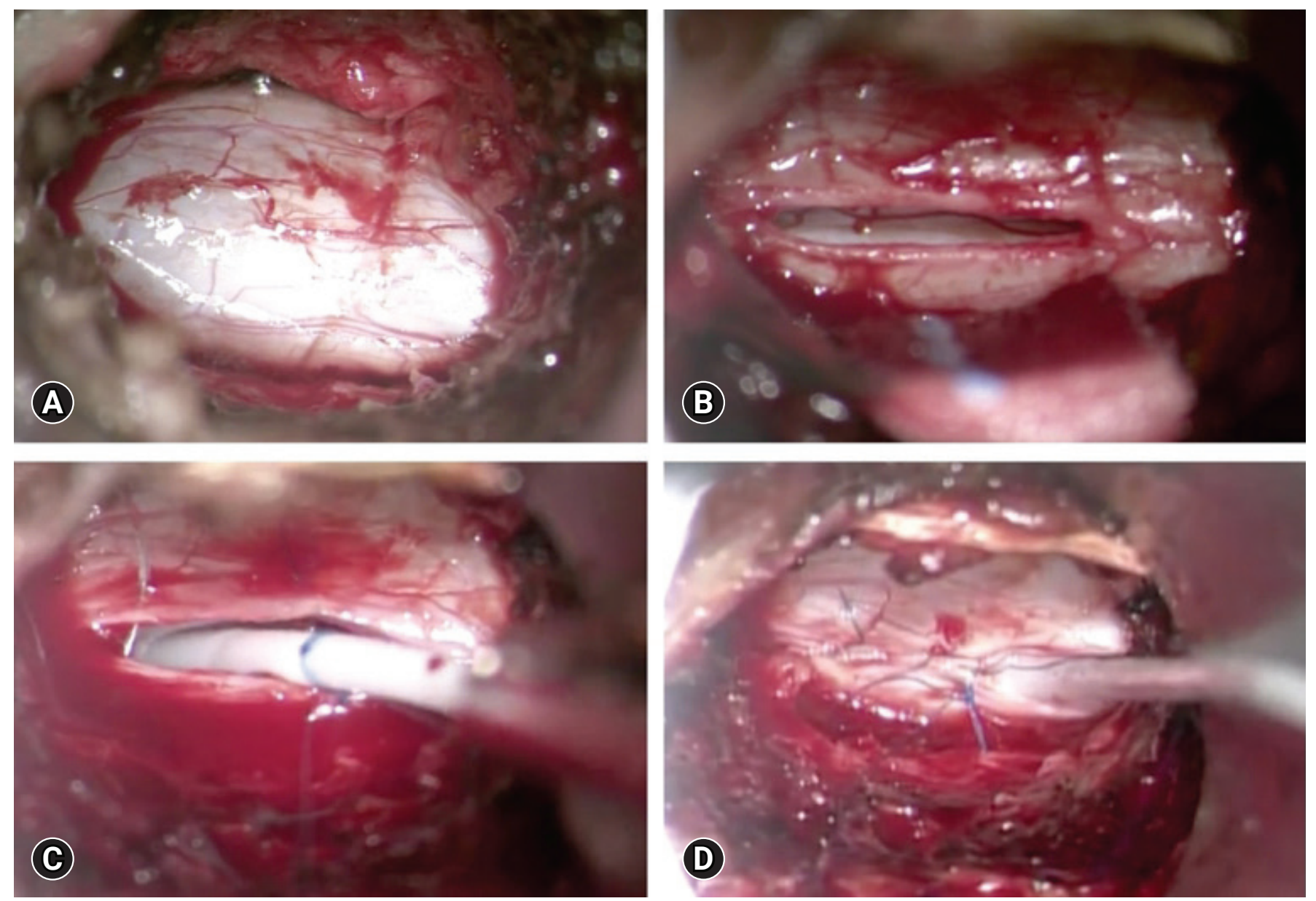

Figure 2. Selected intraoperative images of inserting the syringopleural shunt. (A) Dura was exposed after subperiosteal dissection of paraspinal muscle and a hemilaminectomy at the planned level. (B) A midline durotomy was performed. (C) After inserting the proximal end of the syringopleural shunt into the syrinx cavity, the proximal tube was secured in place with a double-ended 6-0 Prolene ${ }^{\circledR}$ suture through dura edges. (D) Dura was closed primarily under the microscope in a water-tight fashion. 
was then removed gently after ensuring adequate hemostasis, without dislodging the tubing.

A small incision was made over a nearby rib below the hemilaminectomy and a small amount of the superior edge of the rib was removed in an effort to avoid damaging the neurovascular bundle which is located at the inferior aspect of each rib. The pleura was exposed under the microscope, and the tubing was then tunneled into the pleural cavity subcutaneously. Through this procedure, no intraoperative abnormalities were seen and no complications occurred (Figure 2).

Postoperatively the patient's sensory impairment improved gradually. He presented to the emergency department two days post-discharge due to a headache with nausea and vomiting. This was thought to be related to a transient change in intracranial pressure after the insertion of a syringopleural shunt. The headache improved with conservative management and did not require hospitalization. He sustained no other postoperative complications nor neurological decline to date. A follow-up MRI of the spine done 6 months postoperatively showed a significant decline in the size of the syrinx (Figure 1C, D). He remained neurologically unchanged during his follow up period.

\section{RESULTS}

\section{Institutional Cohort}

Through our retrospective chart review, we identified a total of ten procedures performed in nine patients (mean age: 52.3;
4 females, 5 males) by the senior author (Table 1). Etiologies of syringomyelia included post-traumatic, Chiari malformation, idiopathic, and diastematomyelia. All patients underwent correction of underlying etiologies prior to insertion of syringopleural shunts. Patients with Chiari malformation underwent foramen magnum decompression and subsequent magnetic resonance imaging (MRI) demonstrating patency of CSF flow at the foramen magnum, prior to being considered for insertion of syringopleural shunts.

The mean follow-up duration was 7.2 years (range 2.1-12.0 years). In this follow-up period, six patients (67\%) improved neurologically (cases 1-6), one requiring a shunt revision after two years (case 6). The remaining three patients (33\%) had halted progression of myelopathy (cases 7-9), one of which underwent an MIS syringopleural shunt revision due to the multilobulated nature and recurrence of their syrinx over time (case 7).

Seven patients $(78 \%)$ did not have any perioperative complications (cases 1-4, 6, 7, 9). One patient sustained a major complication (case 8). This patient had immediate postoperative flaccid paralysis in the lower extremities requiring urgent removal of the shunt, which was done after hematomyelia and epidural hematoma were ruled out with an urgent MRI. Subsequent follow up MRI did not reveal evidence of cord edema or infarct. The patient had immediate motor improvement after the shunt removal and slowly returned to his neurological baseline. The fact that this patient regained his motor power immediate after shunt removal suggest possible mechanical compression by the shunt as the cord was thin and perhaps

Table 1. Patient characteristics

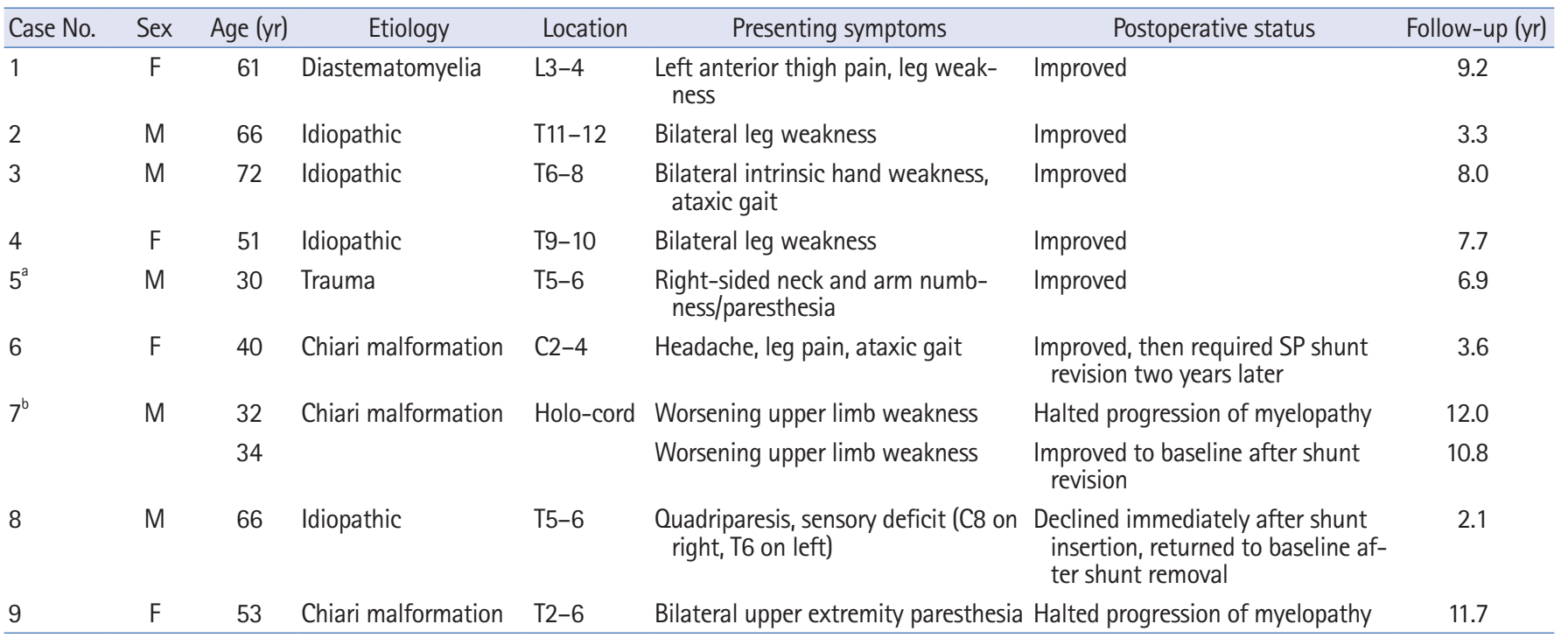

a) Illustrative case.

${ }^{b}$ This patient had two prior open syringopleural shunts placed. 
susceptible to even minor compression. Another patient presented to the emergency department two days post-discharge with a headache without CSF leak (case 5). His headache quickly resolved with conservative management and did not require hospital admission. Regarding disposition, eight patients (89\%) were discharged home on the day of surgery (4-6 hours postoperatively) with appropriate pain control (cases $1-7,9)$. The only patient who was not discharged on the same day was the patient who sustained an immediate postoperative complication (case 8). In all cases, there was no perioperative mortality, pulmonary edema, pulmonary embolism, CSF leak, wound infection, or deep vein thrombosis.

\section{DISCUSSION}

Traditional open syringomyelia shunting procedures often involve a midline incision, bilateral muscle dissection, and a laminectomy to access the syrinx [19]. This often entails a hospital admission for pain control and up to 24 hours of bed rest to prevent CSF leak. We adapted the MIS technique in the hopes of minimizing postoperative pain control and length of hospital stay, and experienced preliminary success in MIS syringopleural shunts in nine patients with a mean follow up of 7.2 years.

There has been an increasing number of reports on MIS in the treatment of intradural pathologies in the past decade [20]. Our group has previously described the use of MIS with tubular retractors to remove both intra- and extra-dural neoplasms as well as for foramen magnum decompression [21,22]. Tredway et al. [23] presented a series of 3 patients in whom they used an MIS approach for the treatment of tethered cord syndrome. Gandhi and German [14] reported 27 MIS procedures in the treatment of a variety of intradural pathologies, including oncology cases, arachnoid cysts, and syrinx.

Compared to that of syringosubarachnoid shunts [14-16], MIS techniques have been less utilized in the placement of syringopleural shunts. Two other studies were found in literature to date which utilised MIS approaches for the insertion of syringopleural shunts. A study by Bonatti and Kurtom [17] reported three cases (in two patients) of thoracoscopic assisted placement of the distal end of the catheter, which was generally well tolerated, with one patient showing immediate postoperative improvement, and the other showing cessation of disease progression after a redo procedure. Guest et al. [18] reported seven cases of a percutaneous endoscopic approach for placement of the syringopleural or cystoperitoneal shunts. In their series, five of the patients underwent syringopleural shunting with distal endoscopic assistance and all improved postoperatively. Three patients underwent conversion to open laminectomy for the placement of the proximal catheter due to failure to identify the arachnoid plane. In comparison, our series showed a durable benefit in a larger number of patients who underwent insertion of syringopleural shunts utilizing Quadrant ${ }^{\mathrm{TM}}$ retractors under the microscope, without having to convert to an open approach.

All patients in our series presented with symptoms of myelopathy attributed to the syrinx. Additionally, all patients underwent correction of underlying etiologies before shunting the syrinx, such as Chiari decompression and stabilization of traumatic fractures. After insertion of syringopleural shunts, a sustained neurological improvement was seen in $67 \%$ of patients. This rate of improvement is in line with the existing literature on outcomes from syringopleural shunting. Case series from 1987 onward involving open syringopleural shunting procedures have reported a rate of neurological improvement ranging from $28.6 \%$ to $81 \%$ with variable lengths of follow-up [10,2426]. For example, in a case series by Sgouros and Williams [10] involving 56 syringopleural shunting procedures, sustained neurologic improvement was seen in $53.5 \%$. In a more recent 2012 case series consisting of 44 patients, $81.8 \%$ sustained neurologic improvement through a follow-up ranging from 1.5 to 17 years [25].

Studies on open procedures for syringopleural shunting report a variety of complications including intracranial hypotension, symptomatic pleural effusion, pneumothorax, infection, shunt malfunction, shunt migration and others [25-31]. In this study, all patients underwent the planned procedure without the need to convert to open. Additionally, all patients underwent primary dural closure and no postoperative CSF leaks occurred that required intervention. Two patients (22\%) developed postoperative complications, one of which was serious. In a relatively large series, which consisted of 44 patients, Isik et al. [25] reported a complication rate of $31.8 \%$. These complications included one count of symptomatic pleural effusion and one count of late postoperative low-pressure headache. Another large series consisting of 56 patients who underwent syringopleural shunting reported a complication rate of $26.7 \%$, which included three cases of shunt blockage, one case of shunt migration causing low-pressure headache, and one case of an alveolar fistula [10]. Therefore, notwithstanding the limited cases in our series, the $22 \%$ overall complication rate in our study is comparable to that of the complication rates in series with open procedures.

This study is limited by the small patient number and its 
retrospective nature. Moreover, as this was a retrospective design, the consistent use of a validated outcome measure tool is lacking with possible introduction of information bias. However, our data suggest that this MIS approach for syringopleural shunting can have similar efficacy and complication rates to that of traditional open procedures while sustaining the potential benefits of MIS, including less postoperative pain and shorter hospital stay. This is evidenced by well- same-day discharge in all but one patient. Thus, this report warrants further studies tolerated assessing the potential benefits of this MIS technique for syringopleural shunting.

\section{CONCLUSIONS}

MIS technique for syringopleural shunting is feasible in appropriately selected patients. Future work is required to comprehensively compare this approach to other MIS and open techniques for syringopleural shunting.

\section{CONFLICT OF INTEREST}

No potential conflict of interest relevant to this article.

\section{REFERENCES}

1. Bogdanov EI, Mendelevich EG. Syrinx size and duration of symptoms predict the pace of progressive myelopathy: retrospective analysis of 103 unoperated cases with craniocervical junction malformations and syringomyelia. Clin Neurol Neurosurg 2002;104:90-97.

2. Brickell KL, Anderson NE, Charleston AJ, Hope JK, Bok AP, Barber PA. Ethnic differences in syringomyelia in New Zealand. J Neurol Neurosurg Psychiatry 2006;77:989-991.

3. Moriwaka F, Tashiro K, Tachibana S, Yada K. [Epidemiology of syringomyelia in Japan--the nationwide survey]. Rinsho Shinkeigaku 1995 35:1395-1397. Japanese

4. Weier K, Naegelin Y, Thoeni A, Hirsch JG, Kappos L, Steinbrich W, et al. Non-communicating syringomyelia: a feature of spinal cord involvement in multiple sclerosis. Brain 2008;131:1776-1782.

5. Roy AK, Slimack NP, Ganju A. Idiopathic syringomyelia: retrospective case series, comprehensive review, and update on management. Neurosurg Focus 2011;31:E15.

6. Anderson NE, Willoughby EW, Wrightson P. The natural history and the influence of surgical treatment in syringomyelia. Acta Neurol Scand 1985;71:472-479.

7. Boman K, livanainen M. Prognosis of syringomyelia. Acta
Neurol Scand 1967;43:61-68.

8. Porensky P, Muro K, Ganju A. Nontraumatic cervicothoracic syrinx as a cause of progressive neurologic dysfunction. J Spinal Cord Med 2007;30:276-281.

9. Brodbelt AR, Stoodley MA. Post-traumatic syringomyelia: a review. J Clin Neurosci 2003;10:401-408.

10. Sgouros S, Williams B. A critical appraisal of drainage in syringomyelia. J Neurosurg 1995;82:1-10.

11. Colak A, Boran BO, Kutlay M, Demirican N. A modified technique for syringo-subarachnoid shunt for treatment of syringomyelia. J Clin Neurosci 2005;12:677-679.

12. Kawaguchi Y, Yabuki S, Styf J, Olmarker K, Rydevik B, Matsui H, et al. Back muscle injury after posterior lumbar spine surgery. Topographic evaluation of intramuscular pressure and blood flow in the porcine back muscle during surgery. Spine (Phila Pa 1976) 1996;21:2683-2688.

13. Schaan M, Jaksche H. Comparison of different operative modalities in post-traumatic syringomyelia: preliminary report. Eur Spine J 2001;10:135-140.

14. Gandhi RH, German JW. Minimally invasive approach for the treatment of intradural spinal pathology. Neurosurg Focus 2013;35:E5.

15. O'Toole JE, Eichholz KM, Fessler RG. Minimally invasive insertion of syringosubarachnoid shunt for posttraumatic syringomyelia: technical case report. Neurosurgery 2007 61:E331-E332. discussion E332

16. Srikantha U, Hari A, Lokanath YK, Varma RG. Syringo-subarachnoid shunt placement: a minimally invasive technique using fixed tubular retractors-three case reports and literature review. Int J Spine Surg 2020;14:133-139.

17. Bonatti HJ, Kurtom KH. A simple technique for thoracoscopic assisted placement of the distal limb of syringopleural shunts. Respir Med Case Rep 2018;25:235-238.

18. Guest JD, Silbert L, Casas CE. Use of percutaneous endoscopy to place syringopleural or cystoperitoneal cerebrospinal fluid shunts: technical note. J Neurosurg Spine 2005;2:498-504.

19. Cacciola F, Capozza M, Perrini P, Benedetto N, Di Lorenzo N. Syringopleural shunt as a rescue procedure in patients with syringomyelia refractory to restoration of cerebrospinal fluid flow. Neurosurgery 2009 65:471-476. discussion 476

20. Kim YB, Hyun SJ. Clinical applications of the tubular retractor on spinal disorders. J Korean Neurosurg Soc 2007;42:245-250.

21. Haji FA, Cenic A, Crevier L, Murty N, Reddy K. Minimally invasive approach for the resection of spinal neoplasm. Spine (Phila Pa 1976) 2011;36:E1018-E1026.

22. Zagzoog N, Reddy KK. Use of minimally invasive tubular retractors for foramen magnum decompression of chiari mal- 
formation: a technical note and case series. World Neurosurg 2019;128:248-253.

23. Tredway TL, Santiago P, Hrubes MR, Song JK, Christie SD, Fessler RG. Minimally invasive resection of intradural-extramedullary spinal neoplasms. Neurosurgery 2006 58:ONS52ONS58. discussion ONS52-ONS58

24. Fan T, Zhao X, Zhao H, Liang C, Wang Y, Gai Q, et al. Treatment of selected syringomyelias with syringo-pleural shunt: the experience with a consecutive 26 cases. Clin Neurol Neurosurg 2015;137:50-56.

25. Isik N, Elmaci I, Isik N, Cerci SA, Basaran R, Gura M, et al. Long-term results and complications of the syringopleural shunting for treatment of syringomyelia: a clinical study. Br J Neurosurg 2013;27:91-99.

26. Williams B, Page N. Surgical treatment of syringomyelia with syringopleural shunting. Br J Neurosurg 1987;1:63-80.

27. Batzdorf U, Klekamp J, Johnson JP. A critical appraisal of syrinx cavity shunting procedures. J Neurosurg 1998;89:382-388.

28. Erdal M, Plikcioglu AC, Bikmaz K, Cøsar M.. Dandy-Walker complex and syringomyelia in an adult: case report and discussion. Neurosurgery 2003 52:1504-1505. author reply 1505

29. Sgouros S, Williams B. Management and outcome of posttraumatic syringomyelia. J Neurosurg 1996;85:197-205.

30. Summers JC, Vellore Y, Chan PC, Rosenfeld JV. Intracranial hypotension after syringopleural shunting in posttraumatic syringomyelia: case report and review of the literature. Asian J Neurosurg 2015;10:158-161.

31. Williams B, Sgouros S, Nenji E. Cerebrospinal fluid drainage for syringomyelia. Eur J Pediatr Surg 1995;5 Suppl 1:27-30. 